\title{
O Patrimônio cultural do Morro do Amaral no imaginário dos jovens: tensões possíveis
}

\author{
The cultural heritage of "Morro do Amaral" in imaginary youth: \\ tensions possible
}

Adilson Aviz ${ }^{1}$

\begin{abstract}
Resumo
Neste artigo, o patrimônio cultural da ilha do Morro do Amaral, localizada em Joinville, norte de SC, às margens da baía da Babitonga, é investigado de forma interdisciplinar através do discurso dos jovens da região mediante a aplicação de entrevistas semiestruturadas. O imaginário, arraigado ao real e ao simbólico (RSI), é o ponto de discussão entre os discursos de preservação do patrimônio cultural e a relação com as sensações temporais nesse espaço preservado da cidade. É utilizado como referencial teórico a psicanálise de Freud e Lacan através dos conceitos de desenvolvimento psíquico em três fases: simbiose, complexo de Édipo e jogo do espelho. Essas fases são vistas de forma dinâmica e não estanques. Utiliza-se para compreensão das falas a análise do siscurso (AD) de Pêcheux em uma corrente francesa de teóricos. As respostas dos jovens mostraram uma relação simbiótica com o local no sentido parcial de conhecimento em relação ao patrimônio cultural, ao mesmo tempo em que se tornam passivos a aceitar aquilo que provoca um sentimento ambivalente entre desejo e medo repetindo discursos préestabelecidos historicamente.
\end{abstract}

Palavras-chave: Patrimônio cultural. Memória. Políticas de preservação. Juventudes. Psicanálise.

\begin{abstract}
In this article the Cultural Heritage of the Island of Morro do Amaral, located in Joinville - SC, north of the shores of the bay Babitonga, is investigated in an interdisciplinary way through the speech of young people of the region through the application of semi-structured interviews. The Imaginary and the Real rooted to Symbolic (RSI) is the point of discussion between the discourses of preservation of Cultural Heritage and the temporal relationship with the sensations that space preserved city. It is used as a theoretical psychoanalysis of Freud and Lacan through the concepts of psychic development in three phases: Symbiosis, Oedipus Complex and Game Mirror. These phases are viewed as a dynamically and not watertight and these are used to understanding the speech Discourse Analysis (DA) of a current Pêcheux French theorists. The responses of young people showed a symbiotic relationship with the local in the sense of partial knowledge in relation to Cultural Heritage at the same time they become liabilities to accept what provokes an ambivalent feeling between desire and fear repeating speeches pre-established historically.
\end{abstract}

\footnotetext{
${ }^{1}$ Universidade da Região de Joinville - UNIVILLE. E-mail: adilson.aviz@gmail.com

Cad. de Pesq. Interdisc. em Ci-s. Hum-s. Florianópolis, Santa Catarina, Brasil, ISSN 1984-8951 v.14, n.105, p.165-186, ago/dez 2013
} 
Key Words: Cultural Heritage. Memory. Preservation policies. Youths. Psychoanalysis.

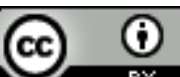

Esta obra foi licenciada com uma Licença Creative Commons - Atribuição 3.0 Não Adaptada.

\section{Introdução}

A ilha do Morro do Amaral se encontra no extremo sul de Joinville, SC - uma cidade que experimenta um presente marcado pelo complexo fluxo de migrantes, tecnologias, informações midiáticas e desejos de preservação de um passado, de memórias que organizam uma suposta unicidade, uma plenitude identitária sempre ausente. Desde os anos de 1980, como analisa a historiadora Coelho (2011), a cidade viveu uma reestruturação das indústrias, o aumento do emprego industrial e a inclusão de novas tecnologias e atualizações no processo produtivo e de comunicação, e essas evidências "incidem sobre os deslocamentos humanos para a cidade e também sobre os multifacetados relacionamentos sociais da urbe" (COELHO, 2011, p. 30-31). Tais aspectos não podem ser desconsiderados nesse artigo que busca analisar o imaginário dos jovens sobre o patrimônio cultural da ilha do Morro do Amaral.

Por que falar/discutir a relação dos jovens com o patrimônio cultural? E por que a região do Morro do Amaral? Esse artigo é um recorte dos resultados de uma pesquisa interdisciplinar intitulada "O patrimônio cultural do Morro do Amaral no imaginário dos Jovens: tensões possíveis" ${ }^{2}$, que nasceu desdobrada de outras pesquisas e trabalhos de extensão anteriores, ${ }^{3}$ aliada a uma inquietação sobre a

\footnotetext{
${ }^{2}$ Pesquisa de dissertação do Mestrado Interdisciplinar em Patrimônio cultural e Sociedade, orientada pela Dra. Raquel ALS Venera e defendida em 26 abril 2013.

${ }^{3} \mathrm{Em} 2008$, realizamos uma pesquisa envolvendo três jovens do sexo masculino com a idade de 18 anos, na intenção de averiguar a importância da função paterna na autoestima e independência de jovens prestes a se inscreverem naquilo que o código civil afirma ser pertencente a maior idade, como trabalho de conclusão de curso na graduação em psicologia. Em 2009, participamos de um trabalho desenvolvido na ilha do Morro do Amaral com alguns jovens. A proposta para esse grupo foi desenvolvida mediante a relação estabelecida no decorrer dos encontros. Dinâmicas envolvendo "contação" de histórias e jogos mostraram uma peculiaridade nesses jovens, a dificuldade de romper o concreto pela fantasia. Em meio a discussões políticas envolvendo a região em torno da preservação versus modernização, os jovens sinalizavam um local alheio aos aspectos físicos sob a égide do aqui-e-agora.
}

Cad. de Pesq. Interdisc. em Ci-s. Hum-s. Florianópolis, Santa Catarina, Brasil, ISSN 1984-8951

v.14, n.105, p.165-186, ago/dez 2013 
relação estabelecida entre sujeito e patrimônio cultural. Os resultados parciais apresentados aqui foram construídos, sobretudo, a partir do diálogo entre a psicanálise e a história, entendendo que o campo do patrimônio cultural se constitui interdisciplinar. Nosso interesse, nesse artigo, está no estudo do Imaginário para concatenar aspectos que possam explicar a relação dos jovens com o patrimônio cultural num processo de memória e identidade de um passado feito presente. Nossa questão problema é a relação de identificação dos jovens com o patrimônio cultural do Morro do Amaral.

O historiador Le Goff (1992) fala sobre o "objeto da história" que é diferente da história dos historiadores e que é reconhecido "nas produções do imaginário uma das principais expressões da realidade histórica e nomeadamente da sua maneira de reagir perante o seu passado" (LE GOFF, 1992, p. 49). A construção imaginária é subjetiva, própria e peculiar, entrelaçada as bases materiais, ${ }^{4}$ isto é, envolvida ao real contemporâneo e aquilo que se tem como simbólico na memória individual ao coletivo.

Entendemos, a partir de Lacan (1998), que o imaginário é algo em extrema relação com o real e o simbólico. O imaginário é constituído a partir da relação entre o real, àquilo que provém da relação fusional, passando pela privação - castração ${ }^{5}$ e entre o simbólico, que está constituído e que é da ordem coletiva - leis e cultura.

O real nessa perspectiva é tudo aquilo que não é simbolizado, aquilo que não pode ser explicado coletivamente. "A construção social da realidade implica em um mundo que pode ser designado e falado com as palavras fornecidas pela linguagem de um grupo social. O que não pode ser dito na sua linguagem não é parte da realidade desse grupo" (CORREIA, 2005, p. 100). Por isso, o real não é a mesma coisa que realidade, porque ao não ser simbolizado não faz parte do coletivo e, por conta disso, sobra, isto é, constitui o resto daquilo que é significado pela linguagem e essa entendida pelo social.

\footnotetext{
${ }^{4}$ Entendemos por bases materiais as condições sociais, econômicas e políticas que caracterizam um dado momento histórico, pelos quais proporcionam experiências de subjetividade privada, isto é, experiências íntimas com acesso restrito e conteúdos exclusivos.

${ }^{5}$ A rigor, castração ou complexo de castração, diz respeito a uma diversidade de crenças e emoções assumidas pela criança em torno da submissão a alguém que the prove ter aquilo (falo) de que precisa para assumir sua posição inicial de completude (simbiose), nesse sentido, serve para definir uma identidade sexual. Sendo assim, "a castração torna-se o símbolo da diferença sexual, e a superação da ameaça de castração determina uma identidade em lugar da outra" (WARD, 2005, p. 35).
} 
A partir disso é possível trabalhar o imaginário como instrumento de compreensão da realidade e da construção subjetiva. A falta ou o excesso de fantasia ${ }^{6}$ pode revelar aspectos destoantes entre o real e o imaginário, em confrontação com a realidade. Sendo assim, é possível detectar os elementos que fazem parte dessa construção em um processo de análise daquilo que entendemos como constituinte coletivo.

Sendo assim, a busca pela compreensão da "relação" entre os jovens da ilha do Morro do Amaral e o patrimônio cultural da região é posicionada pela análise a partir do sujeito e não necessariamente do coletivo socialmente convencionado. $O$ referencial psicanalítico serve de suporte para compreendermos esse sujeito que se constitui único, peculiar, respondendo ao meio de acordo com suas vicissitudes. Do sujeito para o social é o movimento de partida para estabelecer relação entre os aspectos peculiares de ordem psíquica e os comportamentos diversos de ordem sociais respondentes às leis, normas e decretos.

Nessa análise, escolhemos nomear os jovens no plural porque entendemos que o singular estabelece um conceito genérico, que pressupõe pensar alguma coisa em torno de algo estático ou reprodutor de uma prática bem mais complexa. Chamamos de juventudes, a multiplicidade de jovens inseridos em diferentes contextos históricos, marcados pelas desigualdades sociais e diferenças culturais. $\mathrm{E}$ mais do que isso, um significante vazio, plástico a significações que transcendem uma cronologia, inserindo jogos de linguagem e de tempo. Como um estar no mundo, uma estética de existência que ultrapassa as marcas etárias.

Diante do exposto, esse artigo se organiza na apresentação de uma parte da história do patrimônio cultural da ilha do Morro do Amaral, realçando aspectos da relação entre os moradores através da ligação entre sujeito e patrimônio cultural, em um processo de construção subjetiva. Também é apresentado o discurso dos jovens em relação com o patrimônio cultural, e por fim, as considerações finais.

\section{Um pouco da história do patrimônio cultural da ilha do Morro do Amaral}

\footnotetext{
${ }^{6}$ Algo que chamou a atenção no trabalho realizado com os jovens da ilha do Morro do Amaral, em 2009, foi a dificuldade em fantasiar/imaginar situações e ambientes diferentes do cotidiano a partir de uma dinâmica envolvendo uma hipótese de viagem a dois lugares distintos, Amazônia e Nova lorque. Logo em seguida, os jovens montaram um jogo da memória com desenhos criados por eles mesmos sobre "essa imaginação". A grande maioria representou em figuras aspectos relativos ao ambiente da Amazônia e não da cidade Nova lorque.
}

Cad. de Pesq. Interdisc. em Ci-s. Hum-s. Florianópolis, Santa Catarina, Brasil, ISSN 1984-8951 v.14, n.105, p.165-186, ago/dez 2013 
A ilha que hoje é conhecida como Morro do Amaral, reconhecida como um bairro de Joinville, "antes se chamava Riacho Saguaçu. A partir de 1935, passou a adotar a denominação de Morro do Amaral, em virtude das terras pertencentes, em sua grande maioria, à família Amaral” (CORREAA, 1992, p.107). Os habitantes dessa região são narrados como "resultados de uma mistura de portugueses, espanhóis e índios" (ASSUNÇÃO, 1997, D-6, D-7). Nesse sentido, com o afastamento da ilha as famílias foram se estabelecendo entre si.

O acesso era possível apenas pelo mar, pois a mata cobria totalmente a ligação com o resto da cidade, isso dificultava em muito ir à "colônia" em busca de recursos. Essas idas a Joinville ajudava na subsistência, pois a pesca sempre foi a maior atividade econômica da região. Os pescadores comercializavam no Mercado Municipal aquilo que pescavam como "prejereba, pescada, bagre, cação, arraia, camarão, tainha, siri, caranguejo, bacucu, miraguaia" (ASSUNÇÃO, 1997, D-6, D-7).

Na década de 1970, a atividade econômica do Morro do Amaral começou a mudar quando a estrada que liga a ilha ao continente foi construída, dando a oportunidade dos moradores da região saírem para trabalhar nas empresas da cidade. Muitos pescadores trocaram o ofício para trabalhar, principalmente, em empresas ou na própria prefeitura. Porém, anos mais tarde, com o desemprego, muitos foram obrigados a voltar para a pesca.

O lugar é narrado pelos historiadores locais a partir da vista da baia da Babitonga, destacada como uma das belezas que mais chamam a atenção não só dos moradores como dos visitantes, a alegria do povo era representada pelo lazer e as festas, como bem destacadas pelas historiadoras Corrêa e Rosa (1992, p. 108):

no tocante ao lazer, saudosas são as festas que eram realizadas em casas
particulares e "animadas a toque de cavaquinho, violão, rabeca e tambor",
segundo conta D. Vergília. Se traduziam em domingueiras e fandangos, nas
quais dançavam a chama-rita (ou chamarita), a Dança de São Gonçalo,
entre outras. Estas festas começavam mais ou menos às 20 horas e iam até
manhã e nelas eram servidos vinho e queimada. A iluminação do local
consistia em um lampiãozinho. Conta o Sr. Francisco Soares que "os mais
novos não dançavam, ficando a observar o cantador".

Na lembrança dos moradores mais antigos está a memória das tradições que eram preservadas através de festas seguidas pelo Terno de Reis, Boi-de-Mamão, Cavalo-Marinho e Pau-de-Fita. De acordo com um relato de um morador saudosista, 
descrito por Corrêa e Rosa (1992, p.108), "os tempos de antigamente eram melhores, apesar de haver pouco dinheiro e morar em uma casa de palha”.

Com a abertura da rua e a construção da ponte que permite o acesso ao continente, na década de 1970, os ônibus começaram a circular. Em período de maré alta, a ponte que liga a llha ao continente fica intransponível para circulação de automóveis, fazendo com que por horas o Morro do Amaral fique isolado.

Foram descobertos na região três sítios arqueológicos de sambaquis (ASSESSORIA DE IMPRENSA, 2001, p. B-8), segundo edição do jornal A Notícia de 1997, "é o local que mais tem sambaquis da região - os pesquisadores contam dois, mas os habitantes garantem haver mais - é onde os primeiros habitantes da região ribeirinha da Babitonga foi ocupado por civilizações" (ASSUNÇÃO, 1997, D-6). Esses sambaquis são de difícil acesso e ignorados, como relata a reportagem de $A$ Notícia em 10 de outubro de 2001: "O proprietário da área já chegou a sair algemado do local por ter construído casas e cercas em cima do sambaqui, que é patrimônio da união. $\mathrm{Na}$ área também ocorre pisoteio de gado e o único acesso é atravessando a Lagoa do Saguaçu" (ASSESSORIA DE IMPRENSA, 2001, p. B-8). Também foi descoberto na região um cemitério que fica deslocado do ponto central e por não se saber ao certo a origem, suscita algumas crenças ou suposições disseminadas pelos moradores.

A igreja católica do Senhor Bom Jesus, recentemente tombada como patrimônio histórico, nem sempre esteve ali, foi transferida para próximo do mar provavelmente em 1945. "Com a igreja vieram os últimos moradores que resistiam em meio ao mato, onde só uma picada era o caminho para o transporte" (ASSESSORIA DE IMPRENSA, 2001, p. B-8). Os padres vinham de São Francisco do Sul, uma cidade portuária próxima para celebrar os ofícios religiosos (CORREA; ROSA, 1992).

A iluminação era de lampião a querosene e também de velas, essa prática só foi substituída na década de 1990 quando a energia elétrica chegou ao local, assim como a comunicação telefônica, pois o único telefone público existente foi instalado pela prefeitura municipal de Joinville - PMJ na área central (CORREA; ROSA, 1992). Dois fatores importantíssimos, em se tratando de bem estar, que foram disponibilizados muito recentemente. 
Com o decorrer dos anos, o Morro do Amaral sofreu com algumas designações que direta ou indiretamente criaram imbróglios quanto ao impasse entre necessidades da população versus possibilidades legais para suprimir. Foi em 1989 que a localidade recebeu o título de Parque Municipal do Morro do Amaral, criado por decreto municipal n. 6.182 de 1989. Segundo o Instituto de Pesquisa e Planejamento para o Desenvolvimento Sustentável de Joinville - IPPUJ (2011), sua área foi demarcada como 2,7 km² e localizada às margens da Baía da Babitonga, na saída da Lagoa do Saguaçú, respeitando o acesso pela Avenida Kurt Meinert, no agora catalogado bairro Paranaguamirim, zona sul de Joinville.

Os dados atuais descrevem-na também como a ilha do Morro do Amaral, provavelmente agora por causa da maré que, quando alta, isola a região, apresentando características naturais de beleza e proporcionando grande potencial turístico. É vista como um local que abriga sítios arqueológicos, sambaquis e uma comunidade de pescadores artesanais que guardam a história de seus ancestrais (IPPUJ, 2011).

Ao se tornar um parque municipal com reservas naturais, não era possível fazer obras a ponto de descaracterizá-lo. Isso se tornou um problema porque a PMJ não tinha como fazer muita coisa nesse sentido. Cogitou-se a possibilidade em uma discussão sobre o remanejamento dos moradores, o que poderia causar um impacto cultural. Por fim, no dia 3 de abril de 2012, a câmara de vereadores de Joinville aprovou "a recategorização do local até então denominado parque. A ilha do Morro do Amaral agora é uma reserva de desenvolvimento sustentável" (KELLER, 2012).

$\mathrm{Na}$ categoria de parque, os moradores não podiam explorar os recursos naturais e nem modificar os aspectos. Essa condição explica diretamente as queixas e as exigências dos moradores, até então não atendidas. Entretanto, o cumprimento da lei não existia e, para não criar mais conflitos, a situação caminhou até o ponto de se aprovar a atual reserva de desenvolvimento sustentável.

Desde 2007, a Fundação Municipal do Meio Ambiente a FUNDEMA vem levantando dados sobre o local, que, além da aprovação da recategorização, também constatou a presença de "quatro sítios arqueológicos e o tombamento da igreja como patrimônio histórico" (KELLER, 2012). Além dos sambaquis, dos aspectos naturais como o mar, o manguezal, a mata Atlântida, a construção da 
igreja do Senhor Bom Jesus, também é reconhecido popularmente como patrimônio cultural da região, a comida típica e a pesca artesanal.

\title{
2 Relação entre sujeito e patrimônio cultural: uma construção subjetiva
}

Toda relação estabelecida traz consigo conteúdos subjetivos, isso só é possível porque entendemos que cada pessoa se inscreve única e ao mesmo tempo semelhante no mundo, ou seja, ao mesmo tempo em que somos diferentes no modo de pensar, agir, falar, se expor, somos semelhantes na maneira e na capacidade de projetar nossos conteúdos nas diversas relações do cotidiano. O viver em sociedade nos faz confluir para nos tornar aceitáveis através da adaptação a uma comunidade regimentada para uma satisfação coletiva. Ao escrever O Mal-Estar na Civilização, Freud (1997, p. 49) afirma que

\begin{abstract}
a vida humana em comum só se torna possível quando se reúne uma maioria mais forte do que qualquer individuo isoladamente e que permanece unida contra todos os indivíduos isolados. O poder dessa comunidade é então estabelecido como "direito", em oposição ao poder do individuo, condenado como "força bruta". A substituição do poder do individuo pelo poder de uma comunidade constitui o passo decisivo da civilização. Sua essência reside no fato dos membros da comunidade se restringirem em suas possibilidades de satisfação, ao passo que o individuo desconhece tais restrições. A primeira exigência da civilização, portanto, é a justiça, ou seja, a garantia de que uma lei, uma vez criada, não será violada em favor de um individuo.
\end{abstract}

Viver em sociedade e se submeter às leis convencionadas coletivamente muito outrora a sua existência, só passa a ter sentido (na óptica psicanalítica) para o sujeito quando no decorrer das fases de seu desenvolvimento psíquico consegue se ver descolado do outro, nesse caso da mãe, se percebendo como Eu e com condições, a partir de então, de estabelecer identidades.

Se essa diferenciação é importante enquanto base para estabelecimento de identidades e, consequentemente proporcionar um relacionamento social adaptativo, respondente as convenções, nos propomos então a descrever de forma resumida alguns conceitos que nos balizaram nas análises desse artigo. Consideramos como bases de desenvolvimento humano que permitem ao sujeito essa condição de atuar de forma consciente ou não diante de tudo aquilo que enfrenta no cotidiano, pelos quais implicam em responsabilidades representadas em comportamentos ou discursos. Propomos a compreensão da relação entre sujeito e patrimônio cultural a 
partir da explanação teórica das fases de desenvolvimento, sendo elas, a simbiose, o complexo de Édipo e o jogo do espelho.

A simbiose é a fase mais primitiva e intensa experimentada por todas as pessoas. Trata-se dos primeiros meses após o nascimento e constitui um momento de extrema relação entre mãe-bebê, em um sentimento de completude e encantamento, onde não há noção de espaço e tempo a ambos.

Para Mahler, Pine e Bergman (1993, p. 20), o conceito de simbiose consiste na "característica da vida cognitiva-afetiva primitiva, na qual a diferenciação entre o self e a mãe não aconteceu, ou onde ocorreu uma regressão ao estado de indiferenciação self-objeto (que caracteriza a fase simbiótica)". Trata-se de um momento em que o bebê exerce uma relação extremamente única com a mãe, a ponto de não ter a noção de existir por si só. Nesse sentido, é comum que as características subjetivas da mãe sejam reproduzidas pelo comportamento do bebê. O bebê vive a vida da mãe, a ponto de a mãe discernir e interpretar todas as suas necessidades, suprimindo-as.

Aspectos e características da fase simbiótica podem ser vistos e reconhecidos no cotidiano, quando tratamos das relações interpessoais e, em nosso caso, em relação ao patrimônio cultural. Ao expor as "fases", a psicanálise não encerra suas peculiaridades como sendo um período de transição pelo qual não se volta mais. Os aspectos desenvolvidos estabelecem estruturas psíquicas que o sujeito levará consigo e que farão a diferença quanto às interpretações e respostas do cotidiano.

O "pensar terceirizado", uma expressão que utilizamos para descrever alguém que "pensa por", isto é, uma opinião já estabelecida, passa a ser reproduzida como algo pronto. Como em um serviço contratado por uma empresa que está interessada apenas no resultado sem se importar com o processo e muito menos contribuir para isso, é justamente para evitar o labor que se contrata um serviço desses.

Esse "pensar terceirizado" faz com que o sujeito, inconscientemente, procure um estado de conforto, outrora perdido, e pelo qual vive desejando, pois não conseguiu ainda lidar com a frustração de ter que lutar por si só contra aquilo que Ihe causa desconforto. Negar o desconforto faz com que não haja trabalho de contestar, por conta disso, não há posicionamento crítico e sim aceitação. 
Nesse sentido, como podemos estabelecer ligação entre a relação simbiótica e o patrimônio cultural? Levando em consideração o fato de se tratar de algo que por si só traz significados, memórias, identidades e representa uma riqueza da própria humanidade, também exige uma ação de preservação, e essa preservação em muitos casos é imposta como lei. Sendo preciso impor que se preserve um patrimônio cultural, também se entende que não é algo visto da mesma forma por todos, que para algumas pessoas não tem tamanho significado a ponto de merecer preservação ou por existir coisas "mais importantes"” para se interessar.

Conhecer um patrimônio cultural está na implicação de saber ligar tudo aquilo que Ihe convém, conceitos, história, preservação, leis e relação. Nesse sentido, os jovens podem responder a essas questões através de alguns comportamentos que podemos ligar a um estado simbiótico de um "pensar terceirizado" ou não através de identificações. Aberastury e Knobel (1981, p. 31) destacam que "é necessário integrar todo o passado, o experimentado, o internalizado (e também o rejeitado), com as novas exigências do meio". A relação com o atual está intrinsecamente ligada à história de vida de cada um, assim como, à reação às exigências.

A reação diante dos aspectos prontos, o cumprimento das leis, a conceitualização de ideias e a reprodução de práticas comportamentais no cotidiano evidencia as relações simbióticas. A imposição e a disseminação de interesses, paradigmas, preconceitos ou ideias confabulosas de dominação podem instigar comportamento estanque e passivo sem forças de reação, mesmo diante de uma consciência contrária, não há como lutar contra aquilo que ainda não foi vencido ainda que provoque revolta.

Entretanto, na constituição do Eu há paradoxalmente uma sujeição, e, nesse caso, ao que estabelece o rompimento da simbiose e inscreve a frustração, para então se posicionar através de locais que lhe permitem discernir de forma consciente e racional o que lhe apraz. Ao contrário da simbiose que desenvolve uma relação inconsciente de prazer na dependência, é através da passagem pelo complexo de Édipo, que se estabelece o posicionamento consciente de um prazer seletivo, ou seja, o sujeito busca suas fontes de prazer para retornar, mesmo que

\footnotetext{
${ }^{7}$ Essa questão foi motivo de discussão, após visita técnica feita pelos alunos do MPCS, Turma IV da UNIVILLE, ao Sambaqui do Rio Comprido. Os moradores da região mostravam pelo comportamento que estavam preocupados em outras coisas do que com a preservação do local.

Cad. de Pesq. Interdisc. em Ci-s. Hum-s. Florianópolis, Santa Catarina, Brasil, ISSN 1984-8951
}

v.14, n.105, p.165-186, ago/dez 2013 
em momentos rápidos, a sensação de completude que tinha com a mãe e que perdeu, que se estabelece posições independentes críticas.

Freud (1999) usa o mito do Édipo para explicar o processo de diferenciação do Eu como superação do estado de simbiose. Ao reconhecer uma terceira pessoa, o bebê experimenta a imposição do interdito em relação ao investimento afetivo que havia entre a díade mãe-bebê. A função paterna entra em ação promovendo a frustração do desejo.

A partir do momento em que o pai, ou alguém que cumpra essa função no sentido figurado, é inserido na relação, estabelece o Nome-do-Pai ${ }^{8}$ como um representante do que está estabelecido, isto é, do simbólico. Nesse sentido "a função do pai é ser significante que substituiu o significante" (LACAN, 1958 apud DOR, 1991, p. 53), ou seja, o representante de algo já existente muito antes da criança nascer, convencionado e da ordem coletiva através de uma representação real de si mesmo.

Lacan (1958 apud DOR, 1991) chama a atenção para a ideia do pai através do desejo da mãe no processo de permitir o significante do "Nome-do-Pai" que faz então do bebê um sujeito desejante. Dor (1991, p. 54) diz que "o Pai Simbólico, pois só, surge para a criança como pai castrador estritamente na medida em que a criança o investe como um pai doador diante da mãe”. Essa função paterna só é possível exercer por alguém que passou pela castração.

Através da experiência do Édipo surge a noção tríade do real, simbólico e imaginário. Só consegue estabelecer essa noção quem conseguiu sair da simbiose, pois a fusão com o outro impede que haja segurança na tomada de ação e por resultado a dificuldade de expressar autonomia não só no comportamento, mas, principalmente, no pensar.

Em termos de relações cotidianas a fase do Édipo é diferente da simbiose, porque na simbiose o pensar é alheio e no Édipo o pensar é estabelecido. A relação com as leis, a aceitação de outros pontos de vista e a adequação de conceitos próprios como ideias sobre o homem, mundo, conhecimento, vida social, etc., estão imbricadas fortemente na experiência com o Édipo pela função paterna.

\footnotetext{
${ }^{8}$ Sentimento de pertencimento a alguém, ou seja, garantia de ser filho de um pai, ou de ter recebido um nome (sobrenome) que constantemente atualize a experiência da castração.

Cad. de Pesq. Interdisc. em Ci-s. Hum-s. Florianópolis, Santa Catarina, Brasil, ISSN 1984-8951

v.14, n.105, p.165-186, ago/dez 2013
} 
Se a forma que percebemos o mundo e a relação que temos tem a ver com a construção subjetiva a partir do Édipo como uma posição instigada do desejo, sempre em movimento para suprir a "falta", 9 sendo diferente e único, é possível destacar características de comportamentos e discursos envolvendo aquilo que nos propormos investigar nesse trabalho que é a relação com o patrimônio cultural.

Nesse sentido, os lugares de memória, citados por Nora (1993), só são possíveis pela falta, pelo desejo àquilo que não se pode concretizar. Para ele, "o que nós chamamos de memória é, de fato, a constituição gigantesca e vertiginosa do estoque material daquilo que nos é impossível lembrar, repertório insondável daquilo que poderíamos ter necessidade de nos lembrar" (NORA, 1993, p. 15). O patrimônio cultural constituído como um lugar de memória traz consigo o poder de desencadear resignificações a partir do desejo de suprir uma falta, desconhecida e que falsamente parece ser suprida por um prazer qualquer.

É pertinente destacar que para Nora os locais de memória só são de fato por causa dos sentidos da palavra e nesse caso através do "material, simbólico e funcional, simultaneamente, somente em graus diversos. Mesmo um lugar de aparência puramente material, como um depósito de arquivos, só é lugar de memória se a imaginação o investe de uma aura simbólica" (NORA, 1993, p. 21). Um lugar que é significado através do imaginário perenemente ligado ao real e ao simbólico na busca da lembrança daquilo que é impossível lembrar, semelhantemente ao desejo que nos move em direção de algo nunca alcançado por completo.

Candau (2011) afirma que a memória é, acima de tudo, uma reconstrução, algo em constante atualização do passado, sendo assim, mais do que uma reconstrução fiel do mesmo. Em outras palavras, Candau está querendo dizer que essa reconstrução nada mais é do que resignificações a partir de significações. $O$ passado significado, por si só não tem tanta importância do que o presente resignificado, porque se trata de saber o que fazer no aqui-e-agora com aquilo que já foi estabelecido.

\footnotetext{
${ }^{9}$ A eficácia da função paterna em encerrar a simbiose no Édipo, proporciona um vazio, a falta daquilo que preenchia (mãe) a relação e que agora passa a ser um propulsor em direção a busca eterna pela completude. Essa busca que pode ser nomeada didaticamente como "motivação" se torna significações na ordem do desejo, ou seja, todo signo que momentaneamente faz o papel do desejado, porque na real não é o signo em si que satisfaz, mas sim o significado instantâneo e etéreo, que é sobrepujado pela frustração de não ser o suficiente ou da comparação com o concreto daquilo que está no imaginário/desejo.
}

Cad. de Pesq. Interdisc. em Ci-s. Hum-s. Florianópolis, Santa Catarina, Brasil, ISSN 1984-8951

v.14, n.105, p.165-186, ago/dez 2013 
Reconhecer um bem comum como algo rico em cultura não é suficiente para fazer com que alguém se importe em preservá-la. Ter a consciência de preservação, valorizar e se importar com aquilo que temos como patrimônio cultural está para além das normas de proteção ou leis de conservação. Nesse sentido, é preciso estabelecer uma identidade a partir de uma imagem constituída de si em reconhecimento pessoal em meio à estrutura identitária de diferenciação.

Lacan (1998) nomeou o período entre os seis meses até os dezoitos meses como sendo o estádio do espelho. Este estádio compreende aspectos de identificação em termos de absoluta completude, "ou seja, a transformação produzida no sujeito quando ele assume uma imagem - cuja predestinação para esse efeito de fase é suficientemente indicada pelo uso, na teoria, do antigo termo imago" (LACAN, 1998, p. 97). Lacan utiliza a palavra imago para representar a relação do organismo com sua realidade. Ao reconhecer-se no espelho a criança passa a compreender a imagem de seu corpo com aquilo que realmente é, identificando-se consigo mesmo e proporcionando com esse movimento, a capacidade de estabelecer outras identificações.

O estádio do espelho constitui para a criança a fase em que identifica através da imagem - imago - suas fantasias sobre si. Ao elaborar a separação do objeto de desejo na passagem da simbiose ao complexo de Édipo, o bebê internaliza seus limites até identificar-se único e diferente da mãe. O fato de entender que existe por si só e não em dependência total da mãe, a criança chega no estádio do espelho reconhecendo na imagem a figura do outro em si mesma.

A criança se vê refletida no espelho, identifica-se com essa imagem e tornase consciente de que é um ser separado de sua mãe (WOODWARD, 2000). Essa fase é estabelecida entre a linguagem e o simbólico com o imaginário, isto é, constitui uma das primeiras experiências subjetivas, porque compreende a mãe como uma pessoa distinta e separada de si. Isso só é possível por causa da "lei do pai" que rompe com a simbiose proporcionando possibilidades de identificação.

É pertinente comentar que na simbiose a relação entre mãe/bebê não é de identificação, porque não existe separação, há uma confluência entre duas pessoas em uma. A identificação passa a existir na relação pai/bebê quando a criança entende ser diferente da mãe, projetando no pai o desejo de voltar à completude outrora perdida. 
A conclusão dessa fase acontece quando se inicia a possibilidade de identificação com a imago do semelhante, por aquilo que Lacan (1998) chama de "ciúme primordial" ao objeto de desejo - mãe - que transita dialeticamente entre um desejo e outro às situações sociais (LACAN, 1998).

E como pensar o patrimônio cultural a partir dessa visão? Com possibilidades de identificação por aquilo que se tem como experiência no jogo do espelho através da validação entre o que faz sentido, pela imagem identificada no reflexo de si mesmo e pela imposição do superego à valorização, que não permite desconsiderar aquilo que simbolicamente representa a si mesmo. Malgrado, o comportamento contrário, que faz ignorar tudo aquilo que representa o patrimônio cultural em práticas, não só de indiferença, mas de depredação ou de substituição, mostra um fenômeno interessante diante da discussão desenvolvida até aqui sobre dependência, independência e identidades.

\section{0 discurso dos jovens e a relação com o patrimônio cultural}

Como dito anteriormente, esse artigo é um recorte de uma pesquisa que contou com entrevistas de seis jovens entre as idades de 19 e 31 anos, moradores do Morro do Amaral. ${ }^{10} \mathrm{O}$ critério de escolhas dos entrevistados diz respeito a características como: são moradores do Morro do Amaral, já saíram do bairro, já voltaram, nunca saíram, pensam em sair, etc. A pesquisa não se preocupa com quantidades de entrevistas, por ser qualitativa, pois faz parte da obtenção de dados descritivos mediante contato direto e interativo entre pesquisador e a situação do objeto de estudo (NEVES, 2013). O que importa não é a quantidade de amostragem e sim o sentido produzido.

Três dos entrevistados repetiram a ideia quanto a morar no Morro do Amaral, e as falas realçam uma característica peculiar da região: "um bom lugar pra se morar... bem sossegado, não tem muito movimento"; "é bom porque é um lugar calmo"; "acho legal morar aqui, bem sossegado, tranquilo".

Esse lugar sossegado traz a tona uma característica histórica do Morro do Amaral e que, no presente, torna-se significativo por ser uma memória coletiva, "uma representação, uma forma de metamemória, quer dizer, um enunciado que membros

\footnotetext{
${ }^{10}$ Todos os entrevistados assinaram o Termo de Consentimento Livre esclarecido e autorizaram o uso das transcrições em produções acadêmicas.

Cad. de Pesq. Interdisc. em Ci-s. Hum-s. Florianópolis, Santa Catarina, Brasil, ISSN 1984-8951 v.14, n.105, p.165-186, ago/dez 2013
} 
de um grupo vão produzir a respeito de uma memória supostamente comum a todos os membros desse grupo" (CANDAU, 2011, p. 24). Esse aspecto calmo e sossegado está constantemente representado por meio das águas da baia, sem ondas, permite a contemplação serena e uma necessidade de destacar como nos relatos dos antigos moradores (ASSSUNÇÃO, 1997), assim como dos atuais.

No decorrer da história do Morro do Amaral, é possível ouvir palavras de admiração e satisfação de seus moradores pelo lugar, ou por viverem em um ambiente regido pela natureza em termos de vida saudável respirando um ar puro ou pelo sustento que o mar proporciona (ASSSUNÇÃO, 1997). A fala desses jovens parece ecoar, como paráfrase, como repetição do discurso de seus antepassados. "Os processos parafrásticos são aqueles pelos quais em todo dizer há sempre algo que se mantém, isto é, o dizível, a memória. A paráfrase representa assim o retorno aos mesmos espaços do dizer" (ORLANDI, 2010, p. 36).

Um dos entrevistados que teve a experiência de morar por um tempo fora do Morro do Amaral informa que no lugar pra onde foi morar era mais agitado, "eu tinha mais conhecimento lá né? Me dava mais bem com as pessoas assim conversava mais também, saia mais né, tinha mais movimento na verdade né, lá é bem mais movimento, tem mais fervo pra ir... bem mais fervo" (sic). No entanto, preferiu voltar por causa do lugar "calmo e sossegado".

O retorno pode estar mostrando um aspecto simbólico daquilo que vemos na Simbiose, querer estar em uma posição sem frustração, sem desconforto, sem ser exigido. Esse jovem deixa claro que não gosta de incomodo quando diz que no Morro do Amaral "não tem muita encomodação, o cara não se incomoda muito" (sic). Ao ser indagado sobre o que seria esse incomodo ele diz: "ah... vizinho na porta de casa, um vizinho vir na casa do outro direto, que nem lá em casa não vai muito, só eu que saio de vez enquanto" (sic).

O movimento, o agito, as pessoas e o "fervo" parece não ser aquilo que ele quer, porque força uma posição de ação, de uma resposta que ele não quer dar, por isso o retorno ao Morro do Amaral, porque agora ele só sai quando quer. Esse pseudo controle diz respeito a escolher um local "sossegado" que não lhe ofereça riscos de ter que conviver com as diferenças, de ter que conhecer pessoas, pois aqui ele tem a possibilidade de manter um ritmo que seja condizente à sua dinâmica de não incomodar para não ser incomodado. 
Outra participante da pesquisa, uma jovem, liga a característica da simbiose com a necessidade de um "salvador", alguém que venha suprir algumas dificuldades. A ideia que ela tem do local diz respeito a: "um bairro que tem, tem potencial, tem, tem muita coisa a ser explorada, tem muita coisa boa que pode ser tirada daqui, mais que precisa de mais atenção né, da parte do governo, até mesmo dos próprios moradores daqui, se valorizar mais" (sic). Essa perspectiva também é repetida por outra jovem: "olha aqui é um lugar bom pra se viver assim né, só que assim eu to vendo que tá vindo muita coisa ruim de fora e que a gente espera assim pra candidato ${ }^{11}$ tudo né..." (sic).

Esses jovens apresentam em seu discurso, ao mesmo tempo, o desejo de crescimento do local em termos de condições de saúde, escola, acesso, locomoção e lazer e o medo do que pode vir junto, a marginalidade, a violência, a frustração de ter que lidar com aquilo que os outros lidam em lugares alhures. Observa-se na fala deles, esse ir e vir de desejo, pois, enquanto um entrevistado diz que o Morro do Amaral "é o lugar que eu vivo gosto daqui eu não saio" (sic), outro contrapõe: "eu estou lutando por isso... pra sair daqui... na verdade eu nunca saí daqui né, pra sair, pra morar... estou pensando em ir embora pra sempre assim... morar em outro lugar" (sic).

$\mathrm{Na}$ simbiose, quem resolve os problemas é o outro, aquele pelo qual se investe confiança. Percebe-se que, em alguns momentos, na fala desses jovens, fica o desejo de que as coisas mudem, mas por intermédio de um "salvador", alguém que faça alguma coisa pelo bem dos moradores. A esperança nesse outro salvador aparece na frase: "a gente espera assim pra candidato tudo..." (sic), pois se isso não ocorrer a única coisa a fazer é ir embora.

Eles falam em "crescer", em "explorar mais" e de valorização, não só dos aspectos naturais, como também dos moradores. Com a recategorização da região para reserva de desenvolvimento sustentável é possível confrontar aquilo que é da ordem do desejo com o real. No entanto, essas falas denotam uma posição inferior em busca de crescer e aparecer, no sentido de encontrar valores nos aspectos da região e dos moradores. Uma busca que parece estar na história, uma memória discursiva que sustenta o dizer em partes de formulações já feitas, mas esquecidas

\footnotetext{
${ }^{11}$ As entrevistas foram feitas próximo ao período eleitoral do município e como de costume, muito candidatos visitaram o Morro do Amaral em campanha contribuindo para fortalecer a esperança de intervenção, por isso o aparecimento dessa temática.

Cad. de Pesq. Interdisc. em Ci-s. Hum-s. Florianópolis, Santa Catarina, Brasil, ISSN 1984-8951 v.14, n.105, p.165-186, ago/dez 2013
} 
e que vão estabelecendo uma história de sentidos. Orlandi (2010) afirma que sobre essa memória o sujeito não tem controle, que os sentidos se constroem de acordo com a falsa certeza de que se sabe do que está falando.

Chamamos a atenção para as "tensões" que essa posição causa pelo choque do não estabelecido para com o exigido. Uma tensão entre o sossego do lugar com o desejo de melhorias. Essas melhorias se chocam com o sossego, porque proporcionam a chegada de estrangeiros que movimentam o lugar, ao mesmo tempo em que frustra ao concretizar um desejo que é fortalecido pela falta. $O$ imaginário cria fantasias que não correspondem com a realidade. Então, nota-se uma identificação desses jovens ao mesmo tempo em que desejam os atributos de outros lugares.

Quando o sossego é afetado parece surgir um sentimento de não pertencimento em duas etapas: primeiro no Morro do Amaral quando esse sossego é ameaçado, e depois nos outros lugares por se acharem estrangeiros, retornando à pátria de origem. Bauman (2005, p. 17) nos ajuda a entender essas questões quando afirma “que o 'pertencimento' e a 'identidade' não têm a solidez de uma rocha, não são garantidos para toda a vida, são bastante negociáveis e revogáveis". Esse movimento de sair em busca de amenizar a frustração de ter perdido o lugar de sossego, se choca com um lugar de não pertencimento.

Nesse caso a tensão é estabelecida quando, diante de duas situações desconfortáveis, surgem a falta de sossego e a busca por recursos para sanar as necessidades, forçam um ir a uma terra estrangeira e voltar para a pátria. Ir para outra terra é conviver com o "fervo", com o "conhecimento" e com o "incomodo", isso parece não ser agradável para quem sai, mas é o desejo de quem ainda não saiu. É atraente quando está na ordem do desejo e se torna desconfortável quando se concretiza.

"As identidades são fabricadas por meio da marcação da diferença. Essa marcação da diferença ocorre tanto por meio de sistemas simbólicos de representação quanto por meio de formas de exclusão social" (SILVA; HALL; WOODWARD, 2000, p. 39). Essas diferenças entre lugares, entre sossego e fervo, entre exclusão e pertencimento, marcas que realçam características de fora em contraste com aquilo que se tem no Morro do Amaral. 
A simbiose, mais uma vez, aparece no relato de uma participante da pesquisa quando expõe comentários que escuta no ônibus: "a gente escuta, sobre o Morro do Amaral, lá é um manguezal eles falam, lá é lugar do manguezal, pra cá nunca presta nada pra eles, portanto isso a gente escuta, mas a gente não vem falando com eles, discutindo no ônibus, a gente fica quieto né" (sic). O estereotipo da simbiose está na não reação, no ficar quieto, afinal não há defensor.

Com relação ao patrimônio cultural existente no local, os jovens da pesquisa apontaram para um único aspecto, o mar. Interessante observar que as respostas dos jovens, com relação às riquezas reconhecidas por eles na região, teve uma marca significativa entre aqueles que sempre moraram no Morro do Amaral e aqueles que tiveram experiência fora. Eles afirmaram: "esse mar maravilhoso aqui, pra pescar, que não falta nada, pra mim a riqueza é esse mar que está aí" (sic); "Riqueza é o... ponto aqui né, ponto turístico aí, a visão" (sic); "É realmente é o mar (risos), não tem explicação é o mar é a bela vista, realmente é isso" (sic).

A ligação entre a riqueza para esses jovens está no concreto, na fartura da "pesca" e na garantia de que "não falta nada" quando se tem essa prática. O mar garante o turismo, abastece os restaurantes e chama as pessoas. Isso é o concreto que sem "explicação", apresenta resultados por si só, não exige maior compreensão sobre perspectivas de futuro com aquilo que pode ser imaginado como possibilidades. Pensar nas outras possíveis atrações turísticas é algo inexistente porque envolve descoberta e pertencimento pelo patrimônio.

"Na relação tensa do simbólico com o real e o imaginário, o sujeito e o sentido se repetem com o real e o imaginário, o sujeito e o sentido se repetem e se deslocam" (ORLANDI, 2010, p. 53). O mar se apresenta como o "salvador", porque atrai visitantes, e isso ofusca as demais riquezas da região, pois, historicamente, construiu-se uma dependência de sustentação, uma simbiose. Nesse sentido, essa memória discursiva sustenta uma estratificação já feita, porém esquecida, e que constrói uma história de sentidos (ORLANDI, 2010).

\section{Considerações finais}

A primeira vista, tem-se como implicação que os jovens do Morro do Amaral não demonstram interesse pelo patrimônio cultural inerente à região, no entanto, constatamos que esses jovens não apresentam conhecimento sobre, pois, sem Cad. de Pesq. Interdisc. em Ci-s. Hum-s. Florianópolis, Santa Catarina, Brasil, ISSN 1984-8951

v.14, n.105, p.165-186, ago/dez 2013 
saber os aspectos culturais e históricos daquilo que existe no local em que vivem, não dá para afirmar que não demonstram interesse.

Entretanto, aspectos identificados outrora como característica passiva continua chamando a atenção. O estado simbiótico que os moradores do Morro do Amaral mostram com o local, no sentido metafórico do termo, através da posição "sossegado e calmo", faz com que muitas coisas sejam identificadas, mas não enfrentadas. Essa relação com o local é metafórica e ao mesmo tempo parcial, porque reconhece um aspecto de identificação com o mar.

Nos jovens entrevistados, não se percebe características de superação dessa dependência, porque não se vêm em condições de reconhecer além mar. Mesmo os que procuram sair acabam voltando pela necessidade de continuar em um local "sossegado e calmo". Esta é a posição na simbiose que permite reproduzir um pensar terceirizado. São pensamentos que não conseguem convencer por si mesmos, necessitam ser reproduzidos.

Interessante observar que esse pensar terceirizado também é aceito de certa forma pela contramão. Comentários infundados sobre o local ou sobre as pessoas são relevados por não terem forças de contestação. Ideias, estigmas e preconceitos são cristalizados sob a égide do pensar terceirizado, e só é possível romper com isso quando se alcança a diferenciação da dependência.

A independência se constitui definitivamente quando se estabelece identidades, quando se observa características de afinidade no outro ou no objeto de desejo. Qual seria a identidade dos moradores do Morro do Amaral? Pode ser estabelecida pelas crises e seria justamente isso que está acontecendo com uma das jovens entrevistadas que quer morar em outro lugar? Isso já aconteceu com outros dois entrevistados que foram e voltaram? Parece que não, permanecem na simbiose.

O Imaginário constitui o não gozo, aquilo que está na ordem do desejo e constitui um possível gozo que não acontece. Os jovens da pesquisa revelaram um desejo que, por hora, se torna equivocado, incongruente à razão, incompreensível quando concretizado, por isso a volta para a pátria. Mas, não é justamente um desejo não compreensível e nunca alcançável que move as pessoas? A "relação" com o patrimônio cultural será possível e significativa quando, na união entre 
conhecimento e cotidiano, houver ganho mútuo entre sujeito e objeto através da identificação.

Reconhecemos que no Morro do Amaral o patrimônio cultural é material e imaterial. Além da igreja, do cemitério, dos sambaquis, etc., também encontramos a receita do peixe, a maneira artesanal de pescar, as festas, etc. No artigo 2 da convenção para a salvaguarda do patrimônio cultural imaterial proclamado pela UNESCO (2013), identificamos que o patrimônio Imaterial é uma transmissão de geração em geração em um processo de recriação constante nas comunidades e grupos em interação com o ambiente, natureza e história através de um sentimento de identidade e continuidade. Nesse sentido, cabe a reflexão sobre, como poderá acontecer registros de patrimônio imaterial em grupos que agem impulsionados por relações simbióticas? 


\section{Referências}

ABERASTURY, A.; KNOBEL, M. Adolescência Normal: um enfoque psicanalítico. Porto Alegre: Artmed, 1981.

ASSESSORIA DE IMPRENSA, Gabinete do Prefeito. Arqueologia a serviço do meio ambiente. Jornal A Notícia, Joinville, 15 out. 2001. p. B-8.

ASSUNÇÃO, L. F. Morro do Amaral: pedaço de paraíso à beira da Babitonga. Jornal A Notícia, Joinville, 11 mai. 1997. AN Cidade, D-6, D-7.

BAUMAN, Z. Identidade: entrevista a Benedetto Vecchi/Zygmunt Bauman. Trad. Carlos Alberto Medeiros. Rio de Janeiro: Zahar, 2005.

CANDAU, J. Memória e Identidade. Trad. Maria Letícia Ferreira. São Paulo: Contexto, 2011.

COELHO, I. Pelas Tramas de uma cidade migrante. Joinville: UNIVILLE, 2011.

CORREAA, R. M.; ROSA, T. F. da. História dos bairros de Joinville. São Paulo: Gráfica Círculo, 1992.

CORREIA, T. M. M. Real, Simbólico e Imaginário em Lacan. Ciências humanas em Revista, v. 3, número especial, p. 100, jun. 2005.

DOR, J. O Pai e sua função em Psicanálise. Trad. Dulce Duque Estrada. Rio de Janeiro: Zahar, 1991.

FREUD, Sigmund. O Mal-Estar na Civilização. Tradução José Octávio de Aguiar Abreu. Rio de Janeiro: Imago, 1997.

FREUD, Sigmund. Totem e Tabu vol. XIII. Rio de Janeiro: Imago, 1999.

IPPUJ, Instituto de Pesquisa e Planejamento para o Desenvolvimento Sustentável de Joinville. Joinville Cidade em dados 2010/2011. Joinville: Prefeitura Municipal, 2011. 
KELLER, A. Morro do Amaral agora é uma Reserva de Desenvolvimento

Sustentável. 2012. Disponível em: <http://www.joinville.sc.gov.br/noticia/1503-

Morro+do+Amaral+agora+\%C3\%A9+uma+Reserva+de+Desenvolvimento+Sustent $\%$

C3\%A1 vel.html>. Acesso em: 6 jul. 2012.

LACAN, J. Escritos. Trad. Vera Ribeiro. Rio de Janeiro: Zahar, 1998.

LE GOFF, J. História e Memória. Campinas: UNICAMP, 1992.

MAHLER, M. S.; PINE, F.; BERGMAN, A. O nascimento psicológico da criança: Simbiose e Individuação. Trad. Jane Araujo Russo. Porto Alegre: Artmed, 1993. p. 20.

NEVES, J. L. Pesquisa Qualitativa: Características, usos e possibilidades. Cadernos de Pesquisa em Administração, São Paulo, v. 1, n. 3, sem. 2. 1996. Disponível em: <http://www.ead.fea.usp.br/cad-pesq/arquivos/c03-art06.pdf>. Acesso em: 30 mar. 2013.

NORA, P. Entre Memória e História: A problemática dos lugares. Trad. de Yara Aun Khoury. Projeto História, São Paulo, n. 10, p. 7-28, dez. 1993 [cópia digital].

ORLANDI, E. P. Análise de Discurso: Princípios e procedimentos. Campinas: Pontes, 2010.

SILVA, T. T. da; HALL, S.; WOODWARD, K. Identidade e diferença: a perspectiva dos estudos culturais. Petrópolis: Vozes, 2000.

UNESCO. Convenção para a salvaguarda do Patrimônio cultural Imaterial: Paris, 17 de outubro de 2003. 2006. Disponível: <http://unesdoc.unesco.org/images/0013/001325/132540por.pdf>. Acesso em: 27 mar. 2013.

WARD. I. Castração. In: Conceitos da Psicanálise v.7. Trad. Ca rlos Mendes Rosa. Rio de Janeiro: Ediouro, 2005, p. 35.

WOODWARD, K. Identidade e diferença: uma introdução teórica e conceitual. In: SILVA, T. T. da. Identidade e Diferença: A perspectiva dos estudos culturais. Petrópolis: Vozes, 2000.

Artigo:

Recebido em: 27/04/2013

Aceito em: 06/12/2013 